\title{
Review on Sustainability of Hybrid Solar Wind Energy System and Unit Optimization
}

\author{
Megha \\ M. Tech. Scholar \\ Department of Electrical \& Electronics Engineering \\ Oriental College of Technology \\ Bhopal, India \\ kumarimegha342@gmail.com
}

\author{
Ranjeeta Khare \\ HOD \\ Department of Electrical \& Electronics Engineering \\ Oriental College of Technology \\ Bhopal, India \\ rkhare18@gmail.com
}

\begin{abstract}
Renewable energy technologies are suitable for off-grid services, serving the remote areas without having to build or extend expensive and complicated grid infrastructure. Therefore standalone system using renewable energy sources have become a preferred option. This paper is a review of hybrid renewable energy power generation systems focusing on energy sustainability. It highlights the research on the methodology, unit sizing, optimization, storage, energy management of renewable energy system.
\end{abstract}

Keywords- hybrid energy system, reliability, cost, unit optimization, storage, energy management.

\section{I.INTRODUCTION}

Rapid depletion of fossil fuels has necessitated an urgent need for alternative sources of energy to cater the continuously increasing energy demand. Another key reason to reduce our consumption of fossil fuels is the growing global warming phenomena. Environmentally friendly power generation technologies will play an important role in future power supply. The renewable energy technologies include power generation from renewable energy sources, such as wind, PV(photovoltaic), MH(micro hydro), biomass, ocean wave, geothermal and tides. In general, the key reason for the deployment of the above energy systems are their benefits, such as supply security, reduced carbon emission, and improved power quality, reliability and employment opportunity to the local people. Since the RE resources are intermittent in nature therefore, hybrid combinations of two or more power generation technologies, along with storage can improve system performance. Hybrid Renewable Energy System (HRES) combines two or more renewable energy resources with some conventional source (diesel or petrol generator) along with storage, in order to fulfill the demand of an area. An example of PV-wind diesel generator HRES is shown in fig. 1 .

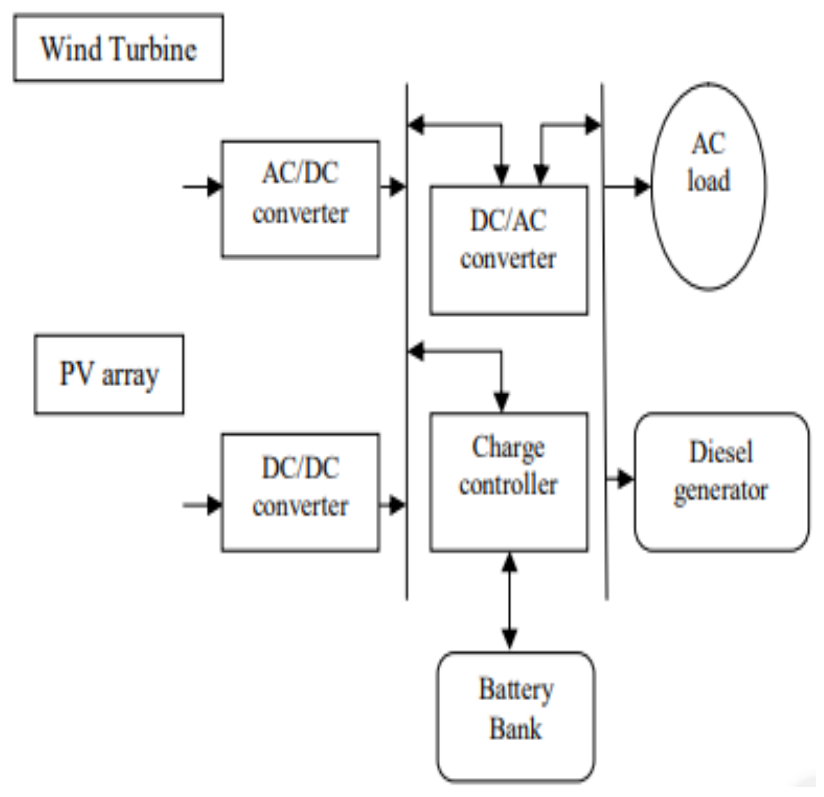

Fig. 1. Block diagram Hybrid Energy

\section{II.LITERATURE REVIEW}

Shahbaz Hussain et al. [1] This paper presents a hybrid renewable energy system that yields minimum total project cost and maximum reliability. The system is in modular configuration consisting of PV array, wind turbine, battery storage, AC load and a dump load. Also, the minimization of unutilized surplus power is taken into consideration as one of the design objectives. In this paper, a new technique named iterative filter selection approach is used in designing the hybrid PV-WT-battery system to obtain the best acceptable solution while considering all the design objectives. The system is then justified by comparing with iterative-pareto-fuzzy technique. The technique is found to be superior in terms of total project cost with satisfaction to the load demand. 
Ranjay Singh et al. [2] The fast-growing awareness of depleting fossil fuel and the adverse impact of conventional energy generation methods on the environment has brought passionate attention to renewable energy sources (RE source). Owing to stochastic nature of energy production from renewable energy system (RES), two or more sources are combined to form hybrid RE system (HRES). Optimisation of size, cost and reliability of power production of HRES are important factors in the planning of HRES. This study presents a review of optimisation tools and constraints on which HRES system is optimised. The types of storage/ backup system available for HRES are also presented in this study.

Rashid Al Badwawi et al. [3] This paper provides a review of challenges and opportunities / solutions of hybrid solar PV and wind energy integration systems. Voltage and frequency fluctuation, and harmonics are major power quality issues for both grid-connected and stand-alone systems with bigger impact in case of weak grid. This can be resolved to a large extent by having proper design, advanced fast response control facilities, and good optimization of the hybrid systems. The paper gives a review of the main research work reported in the literature with regard to optimal sizing design, power electronics topologies and control. The paper presents a review of the state of the art of both grid-connected and stand-alone hybrid solar and wind systems.

Kumaresh Rout et al. [4] the energy demand is increasing with the population growth but the available limited nonrenewable fossil fuel resources unable to meet the demands for a longer period of time. Renewable energy technologies are suitable for off-grid services, serving the remote areas without having to build or extend expensive and complicated grid infrastructure. A combination of two or more renewable energy sources is more effective than a single source in terms of cost, efficiency and reliability. This is called as Hybrid Renewable Energy System (HRES) and is becoming a fast developing market worldwide. This paper is a review of various optimization techniques of hybrid renewable energy systems for power generation.

\section{III.DESCRIPTION OF THE HYBRID SYSTEM}

The generation of both wind power and solar power is very dependent on the weather conditions. Thus, no single source of energy is capable of supplying cost-effective and reliable power [4]. With combine of the renewable systems, it is possible that power fluctuations will be incurred. To mitigate or even cancel out the fluctuations, energy storage technologies, such as storage batteries (SBs) can be employed. The proper size of storage system is site specific and depends on the amount of renewable generation and the load $[5,6]$. The needed storage capacity can be reduced to a minimum when a proper combination of wind and solar generation is used for a given site.

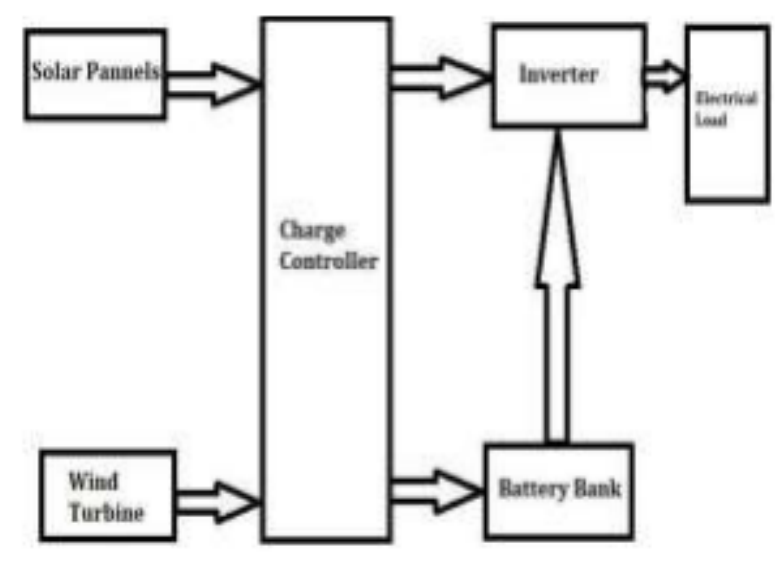

Fig. 2. Block diagram of a hybrid generation unit

\section{IV.ARTIFICIAL INTELLIGENCE}

Artificial Intelligence is an area of computer science that emphasizes the creation of intelligent machines that work and reach like humans. Some of the activities computers with artificial intelligence are designed for include speech recognition, learning, planning, and problem solving. Artificial intelligence methods, such as Artificial Neural Networks, Genetic Algorithm, Fuzzy Logic, PSO (Particle Swarm Optimization, ACO (Ant Colony Optimization) widely used to optimize a hybrid system in order to maximize its economic benefits. Kalogirou proposed an optimization model as solar systems using Artificial Neural Network and Genetic Algorithm. These methods are most successful methods as they help in finding the global solution of complex problems.

\section{V.POWER ELECTRONICS TOPOLOGIES AND CONTROL}

There are two topologies for grid-connected solar PV and wind hybrid system as can be seen from Fig. 1 and Fig. 2. Fig. 1 shows that the DC outputs' voltages from individual solar PV, wind and battery bank stream, through individual $\mathrm{DC} / \mathrm{DC}$ and $\mathrm{AC} / \mathrm{DC}$ units, are integrated on the DC side and go through one common $\mathrm{DC} / \mathrm{AC}$ inverter which acts as an interface between the power sources and the grid to provide the desired power even with only one source available. Hence, the renewable energy sources act as current sources and can exchange power with the grid and the common DC/AC inverter controls the DC bus voltage. The individual units can be employed for maximum power point tracking (MPPT) systems to have the maximum power from the solar PV and wind systems and the common DC/AC inverter will control the DC bus voltage. The battery bank 
is charged when there is an extra power and discharged (by supplying power) when there is shortage of power from the renewable energy sources. Their proposed systems were capable to operate in different modes of operation and able to transfer from one mode to another easily. With the DC bus line output voltage from each converter is set to be fixed and controlled independently in that system, the controller of wind and PV has MPPT functionality whereas the controller of the fuel cell (FC) takes care of compensations of the system for the load power fluctuation. The voltage converters play an important role in controlling the amount and the type of voltage whether AC or DC and the duty cycle of those converters can be used to improve the quality of power. The duty cycle of a DC/DC converter is relatively fast in MPPT control process. They added that the charging current of a battery is changing with the automatic adjustment of duty cycle.

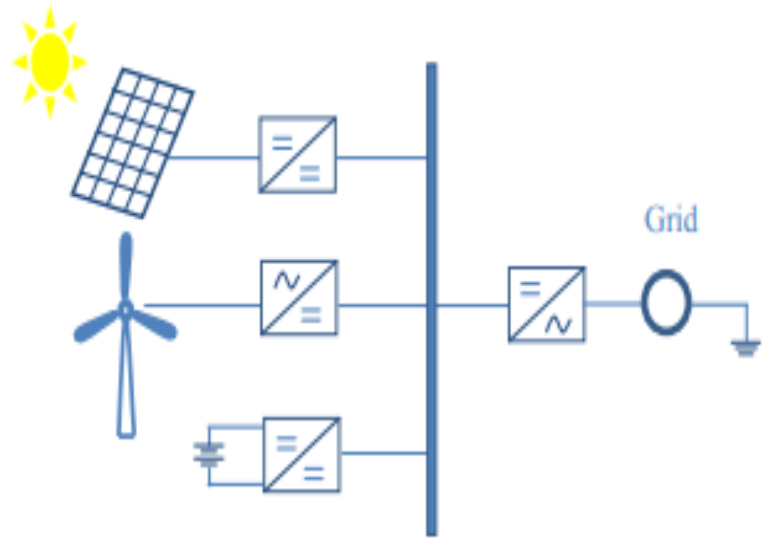

Fig. 3 Grid-connected hybrid system at common DC bus

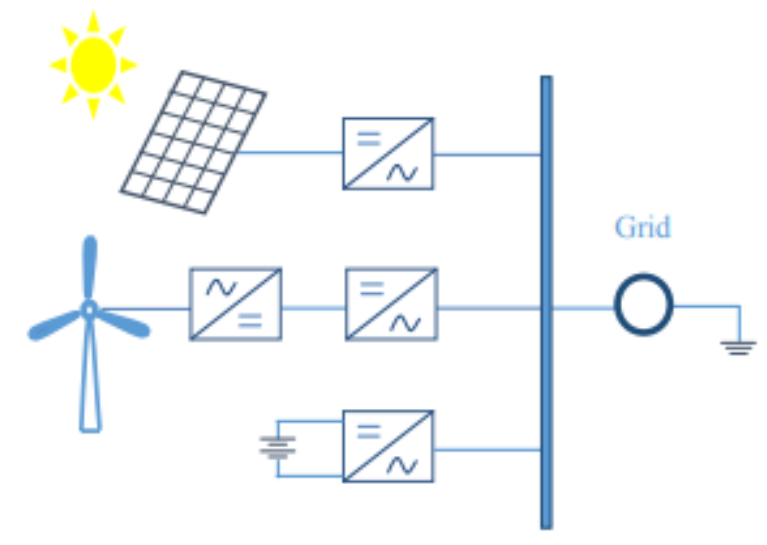

Fig. 4 Grid-connected hybrid system at common AC bus

\section{VI.CONCLUSION}

This paper gives an overview of hybrid renewable energy systems (HRES). Various aspects such as methodology, unit sizing and optimization, storage and energy flow management, are specifically reviewed. Future trends as well as challenges are also presented in the paper. The presented literature review facilitates interested researchers in design and power management of HRES.

\section{REFERENCES}

[1] Shahbaz Hussain, Rashid Al-ammari "Optimisation of hybrid renewable energy system using iterative filter selection approach" Volume 11 Issue 11•1392017.

[2] Ranjay Singh, Ramesh Bansal "A review of hybrid renewable energy systems based on storage options, system architecture and optimization criteria and methodologies" January 2018 DOI: 10.1049/iet-rpg.2017.0603.

[3] Rashid Al Badwawi, Mohammad Abusara "A Review of Hybrid Solar PV and Wind Energy System" Smart Science Vol. 3, No. 3, pp. 127-138(2015).

[4] Kumaresh Rout, Jayanta Kumar Sahu "Various Optimization Techniques of Hybrid Renewable Energy Systems for Power Generation: A Review" Volume: 05 Issue: 07 | July 2018.

[5] S. Bae and A. Kwasinski, "Dynamic modeling and operation strategy for a microgrid with wind and photovoltaic resources," IEEE Transactions on Smart Grid, 3, 1867-1876 (2012) DOI: 10.1109/TSG.2012.2198498.

[6] N. A. Ahmed, A. K. Al-Othman, and M. R. AlRashidi, "Development of an efficient utility interactive combined wind/photovoltaic/fuel cell power system with MPPT and DC bus voltage regulation" Electric Power Systems Research, 81, 10961106 (2011) DOI: 10.1016/j.epsr.2010.12.015. 